\title{
Análise da Influência do Álcali Residual e Sulfato de Sódio Sobre as Propriedades do Licor Negro de Eucalipto.
}

\section{Luísa C. M. Gomes*, Vitor M. V. Cruz, Giovanna S. Proença, José Vicente H. Dangelo.}

\section{Resumo}

Esse projeto avaliou a influência da composição química do licor negro de eucalipto sobre as propriedades físicas (massa específica e sólidos totais) deste. Para isso, foram utilizadas amostras de licor e de lignina de processo Kraft fornecidas pela Suzano Papel e Celulose, comparando os resultados com amostras sintéticas de laboratório.

\section{Palavras-chave:}

Licor negro, Kraft, Lignina.

\section{Introdução}

Com o objetivo de extrair celulose, cavacos de madeira passam pelo processo de polpação e obtém-se como subproduto o licor negro, solução aquosa contendo matéria orgânica (basicamente lignina) e inorgânica $\left(\mathrm{Na}_{2} \mathrm{SO}_{4}\right.$ e $\mathrm{Na}_{2} \mathrm{CO}_{3}$ principalmente). No processo Kraft, esse resíduo é levado a uma unidade de recuperação para geração de energia e reaproveitamento dos químicos inorgânicos. Como muitas indústrias têm gerado uma quantidade de licor superior à capacidade dessas unidades de recuperação, parte desse licor pode ter a lignina extraída para ser reutilizada para outros fins. Entretanto, não há muitos estudos envolvendo licor proveniente da polpação de eucalipto (madeira mais utilizada no Brasil) que focam na influência da composição do licor sobre suas propriedades fundamentais. Nesse trabalho foram realizados experimentos laboratoriais para analisar a influência dos principais componentes do licor negro industrial (lignina, $\mathrm{Na}_{2} \mathrm{SO}_{4} \mathrm{e}$ $\mathrm{Na}_{2} \mathrm{CO}_{3}$ ) sobre duas de suas características físicas mais importantes: massa específica e teor de sólidos, obtendo correlações que possibilitam predizer estas grandezas.

\section{Resultados e Discussão}

Para medição da massa específica, foi utilizada a técnica da picnometria, à temperatura ambiente. Já para a análise dos sólidos totais, utilizou-se aquecimento em estufa a $105^{\circ} \mathrm{C}$ por $24 \mathrm{~h}$, seguindo a técnica descrita em TAPPI T650 cm-99 "Solids content of Black Liquor". Após domínio dessas metodologias a partir de várias análises com licores negros industriais, foram produzidas em laboratório misturas binárias de lignina e sal $\left(\mathrm{Na}_{2} \mathrm{SO}_{4}\right.$ ou $\mathrm{Na}_{2} \mathrm{CO}_{3}$ ). Com os resultados de massa específica e teor de sólidos dessas amostras, foram obtidos com o software Minitab $8^{\circledR}$ modelos preditivos para essas propriedades físicas, seguindo a equação geral a seguir:

$$
P=A+B X_{1}+C X_{2}+D X_{1}^{2}+E X_{2}^{2}+F X_{1} X_{2}
$$

na $P$ seria a propriedade em questão, $X_{1}$ a concentração de um dos sais e $X_{2}$ a concentração de lignina. As constantes de $\mathrm{A}$ até $\mathrm{F}$ encontradas são apresentadas nas Tabelas 1 e 2, além dos valores obtidos experimentalmente para massa específica e sólidos totais das amostras, apresentados nas Figuras de 1 e 2 . As médias dos desvios residuais entre valores medidos $\mathrm{e}$ previstos pelos modelos são próximas a $0,3 \%$ para a massa específica e 2,15\% para o teor de sólidos.
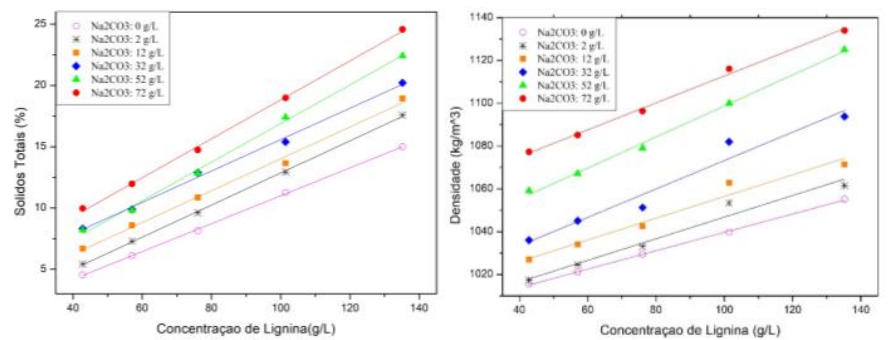

Figura 1. Propriedades em função das concentrações de lignina e $\mathrm{Na}_{2} \mathrm{CO}_{3}$.
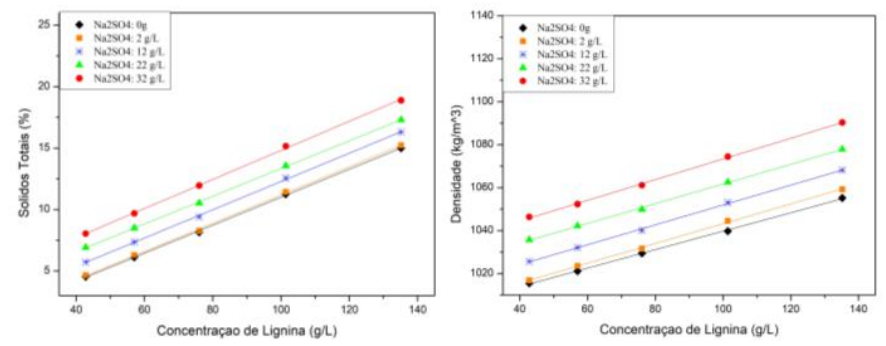

Figura 2. Propriedades em função das concentrações de lignina e $\mathrm{Na}_{2} \mathrm{SO}_{4}$.

Tabela 1. Coeficientes dos modelos com $\mathrm{Na}_{2} \mathrm{CO}_{3}$.

\begin{tabular}{|c|c|c|c|c|c|c|}
\hline \multirow{2}{*}{ Propriedade } & \multicolumn{7}{|c|}{ Coeficientes } \\
\cline { 2 - 7 } & A & B & C & D & E & F \\
\hline $\begin{array}{c}\text { Massa } \\
\text { Específica }\end{array}$ & 1,00283 & 0,000716 & 0,000347 & 0 & 0,000001 & 0,000003 \\
\hline $\begin{array}{c}\text { Sólidos } \\
\text { Totais }\end{array}$ & 0,258 & 0,0878 & 0,10694 & $-0,000632$ & 0,000088 & 0,000496 \\
\hline
\end{tabular}

Tabela 2. Coeficientes dos modelos com $\mathrm{Na}_{2} \mathrm{SO}_{4}$.

\begin{tabular}{|c|c|c|c|c|c|c|}
\hline \multirow{2}{*}{ Propriedade } & \multicolumn{7}{|c|}{ Coeficientes } \\
\cline { 2 - 7 } & $\mathrm{A}$ & $\mathrm{B}$ & $\mathrm{C}$ & $\mathrm{D}$ & $\mathrm{E}$ & $\mathrm{F}$ \\
\hline $\begin{array}{c}\text { Massa } \\
\text { Específica }\end{array}$ & 1,00145 & 0,000736 & 0,000396 & 0,000004 & 0 & 0,000001 \\
\hline $\begin{array}{c}\text { Sólidos } \\
\text { Totais }\end{array}$ & $-0,0510$ & 0,10458 & 0,09563 & 0,000055 & 0,000633 & 0 \\
\hline
\end{tabular}

\section{Conclusões}

Ao analisar o impacto incremental das variáveis $X$, o software mostra que, para a massa específica das misturas contendo $\mathrm{Na}_{2} \mathrm{CO}_{3}$, o sal possui maior influência. Nas outras soluções, o material orgânico apresenta maior impacto na determinação das propriedades físicas. Os desvios residuais dos modelos obtidos são baixos, tornando-os confiáveis para predizer as propriedades.

\section{Agradecimentos}

À Suzano Papel e Celulose, por fornecer amostras de licor e lignina. Ao CNPq, ao prof. D'Angelo e ao Vitor Cruz, por acreditar na minha pesquisa e apoiá-la. 